\title{
Understanding the Transformation to a Knowledge-Based Health Bioeconomy: Exploring Dynamics Linked to Preventive Medicine in Kenya
}

\author{
Ruth Oriama ${ }^{1, *(1)}$ and Andreas Pyka ${ }^{2}$ \\ 1 Bureau d'Economie Théorique et Appliquée (BETA), Université de Strasbourg, 67000 Strasbourg, France \\ 2 Institute of Innovation Economics, Hohenheim University Stuttgart, 70599 Stuttgart, Germany; \\ a.pyka@uni-hohenheim.de \\ * Correspondence: roriama@etu.unistra.fr; Tel.: +254-720-889472
}

Citation: Oriama, R.; Pyka, A.

Understanding the Transformation to

a Knowledge-Based Health

Bioeconomy: Exploring Dynamics Linked to Preventive Medicine in

Kenya. Sustainability 2021, 13, 12162.

https://doi.org/10.3390/

su132112162

Academic Editor: Mihajlo Jakovljevic

Received: 5 August 2021

Accepted: 27 October 2021

Published: 4 November 2021

Publisher's Note: MDPI stays neutral with regard to jurisdictional claims in published maps and institutional affiliations.

Copyright: (c) 2021 by the authors. Licensee MDPI, Basel, Switzerland. This article is an open access article distributed under the terms and conditions of the Creative Commons Attribution (CC BY) license (https:/ / creativecommons.org/licenses/by/ $4.0 /)$.

\begin{abstract}
The bioeconomy transition is seen as a means to achieving industrial competitiveness. Targeted actions on leverage points can have specific effects on transitional changes in system dynamics; these actions have yet to be identified in the context of the knowledge-based health bioeconomy in Kenya. This paper employs system dynamics and grounded theory to identify causations linked to the feedback mechanisms in a complex adaptive system specific to preventive medicine in Kenya. The causal relations identified will allow for extended empirical interrogations. We conducted sixteen semi-structured interviews with key informants using purposive and theoretical sampling. Through these interviews, we obtained detailed information on trends for leverage points for a transition to a bioeconomy in Kenya. We developed three qualitative themes along the structure of information flows, rules, and goals of the system. In addition, we determined the overall perception of the health bioeconomy and elaborated stakeholder-specific applications. We identified a dissociation as a general perception that knowledge generation is the preservation of the public sector. Government effectiveness was found to affect public-service turnaround time, transparency, and regulatory interventions. Finally, we identified weak network failures as the key system failures whose functional deficiencies can be exploited for future policy legitimation.
\end{abstract}

Keywords: economic transitions; bioeconomy; preventive medicine

\section{Introduction}

The feedback governing the transition to a knowledge-based health bioeconomy in preventive medicine in Kenya seems promising, as demonstrated by various policies and programmes for transitioning to sustainability in the new biology that have emerged over time. In the recent past, several policies and programmes have been designed in relation to a knowledge-driven bioeconomy, addressing concepts of health transitions, value, and competitiveness. They include the establishment of the Centre for Traditional Medicines and Drugs Research, set up as part of the Kenya Medical Research Institute (KEMRI) following the World Health Organization's (WHO) Alma-Ata Declaration (1978), which identified primary health care as the key to attaining the goal of "health for all". This declaration promotes the role of healers who often use natural biodiversity resources to provide primary health care [1]. More recent product development partnerships have incorporated concepts of translational medicine and bioeconomy. For instance, International AIDS Vaccine Initiative (IAVI), an initiative focused on developing vaccines and antibodies in and for the developing world to accelerate their introduction in low-income countries, and others are engaging with local health innovation system actors to advance biomedical innovations [2]. While these policies and programmes address emergent issues in the health innovation system, the interaction of system actors has not been elaborated to determine the emergent leverage points towards a knowledge-based health bioeconomy. 
The concept of leverage points is a recurrent theme in sustainability transitions [3-6], referring to "places in complex systems where relatively small changes can lead to potentially transformative systemic change" [6]. Leverage points allow us to study system transitions such as those in a knowledge-based health bioeconomy. In this context, a knowledge-based health bioeconomy, as defined in this study, is perceived as the processes leading to socio-economic improvement through health, biotechnology, and medical applications, whether linked to the use of biologics or to sustainable environmental and biodiversity practices, all of which are considered forms of capital.

Existing systems analyses of the knowledge-based bioeconomy in Kenya have not only focused primarily on agricultural systems, given the sector contributes about $1.6 \%$ to Gross Domestic Product (GDP) growth according to 2020 estimates while industry and services are larger contributors to GDP growth at $3.9 \%$ and $5.9 \%$, respectively [7]. Governance studies on the bioeconomy in the country have taken a policy review approach, especially in light of the imminent East African Bioeconomy Strategy [8,9]. Analyses of the ecosystem using sustainability transitions and the leverage points framework could provide insight into where to intervene. Therefore, employing the bioeconomy paradigm, we explore the leverage points for (i) the structure of information flows in the system, (ii) the rules of the system, and (iii) the goals of the system in preventive medicine for a health bioeconomy transition within Kenya's health research and innovation ecosystem. These insights are drawn from the leverage points framework developed by Meadows [6]. At this stage, preventive medicine is defined as disease prevention and risk factor management. Some of the innovations and procedures involve screening, harm reduction strategies, and chemoprophylaxis [10].

In an exploratory approach, we use configurational theorising as a research design. This approach contrasts with correlational theorising such that as much as we are looking to study the three leverage points, the relationships between the exploratory variables involved in these leverage points are not yet determined or cannot be estimated in advance. Configurational theorising allows us to study interdependencies among such exploratory variables and bring out an outcome of interest [11]. In our approach, we create causal loop diagrams (CLDs) based on insights from sixteen key informant interviews conducted with heterogeneous sector leaders, to bring out outcomes of interest about three leverage points. Participants are representative of the different categories of firms engaged in research and innovation activities that influence the emergence of niches in the health bioeconomy: state-owned R\&D enterprises or academic institutions (research), the private sector (biomass transformation), health practitioners (health system actor), and the government/policymakers (regulation and support) (hereafter collectively referred to as firms) $[12,13]$.

Our findings show that there is a potential leverage point in the structure of information flows. Research is perceived as a preserved role of academia and research institutions. The private sector plays a smaller role. This affects the scale of public-private partnerships for research and innovation.

Secondly, a dynamic set of factors influence firms' decision rules, including: promoting local vaccine manufacturing, gaining relevance in biotechnology, securing funding for research, delivering quality public service, and obtaining data from clinical trials. However, such endeavours face institutional lock-ins, reflected particularly in low governance efficiencies, reduced transparency in the issuance of necessary authorisations, and lengthy government processes.

Finally, using the Woolthuis framework [14], we find that weak network failures are predominantly system failures. These failures are evident where the private sector funded infrastructure/equipment is not paid for on time, where the role of actors is not clearly defined, e.g., when academia intends to take a leading role in research and innovation acceleration and when government institutions are not well specified which leads to regulatory lock-ins. Instruments such as the Budapest Treaty (1997), viewing the bioeconomy only as an enabler of the overall economy rather than as an industry in and 
of itself, and intergovernmental as well as interministerial coordination of bioeconomy governance issues can address such weak network failures.

Our results should be interpreted as a first step towards identifying policy measures for a systemic bioeconomy transition. The positive feedback loops identified can be further investigated using quantitative methods to determine the thresholds for activating system transformations. As for the negative feedback loops, nudge policies can be proposed, or further research can be conducted to understand their underlying inertia.

The remainder of this paper is organised as follows. Section 2 provides background information on the three research objectives of this paper. Section 3 presents the methodological framework and research process, describing the CLDs approach. Section 4 outlines the results of our analysis. In Section 5, we discuss the core themes and leverage points that emerge from our analysis, describing the transition towards a knowledge-based health bioeconomy. Section 6 provides the conclusions and an outlook for future research. Finally, we outline the semi-structured questionnaire used, which is included as an appendix.

\section{Presenting the Three Leverage Points}

Leverage points refer to strategic points within complex adaptive systems where a slight alteration can cause significant system changes and bring about a transition. These are often counterintuitive, and if not, used backwards, systematically worsening the problem they are trying to solve. By adequately studying complex systems, it is possible to identify their leverage points. Meadows introduces a tentative hierarchy of leverage points in order of increasing effectiveness on the system. In Meadow's hierarchy of leverage points, the power to transcend paradigms is presented as the most effective leverage point (see Figure 1):

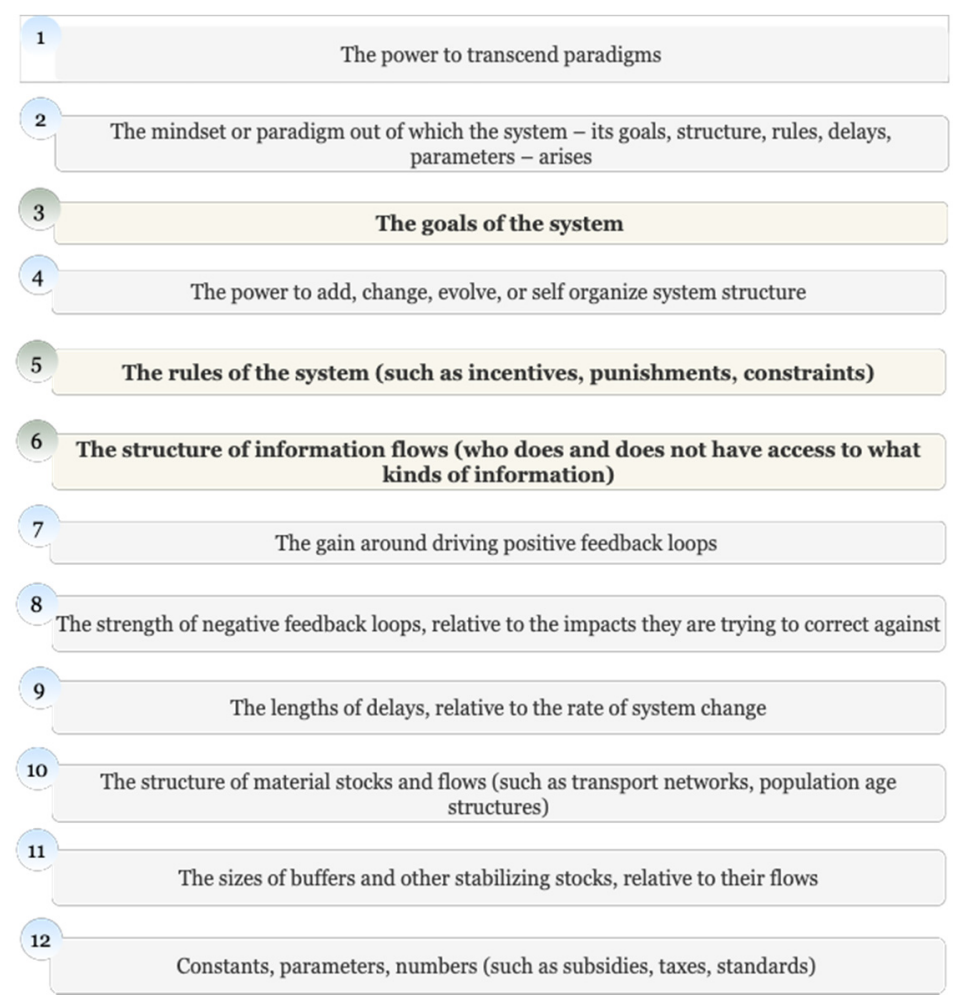

Figure 1. Meadow's hierarchy of leverage points (adopted from [6]).

While some critics argue that this leverage points framework is too complex and hierarchical, its interpretation remains flexible [15]. For instance, the rules of the system as outlined at leverage point five (5) may be reflected in the rates of subsidies, taxes, and standards included in leverage point twelve (12). Moreover, positive feedback loops around any of the other leverage points might occur, whose gains may be reflected as represented 
in leverage point seven (7) and so on. We expect the dynamics of the feedback loops identified for (i) the structure of information flows in the system, (ii) the rules of the system, and (iii) the goals of the system in preventive medicine for a health bioeconomy transition within Kenya's health research and innovation ecosystem to provide information about the leverage points for a bioeconomy transition (see Figure 2).

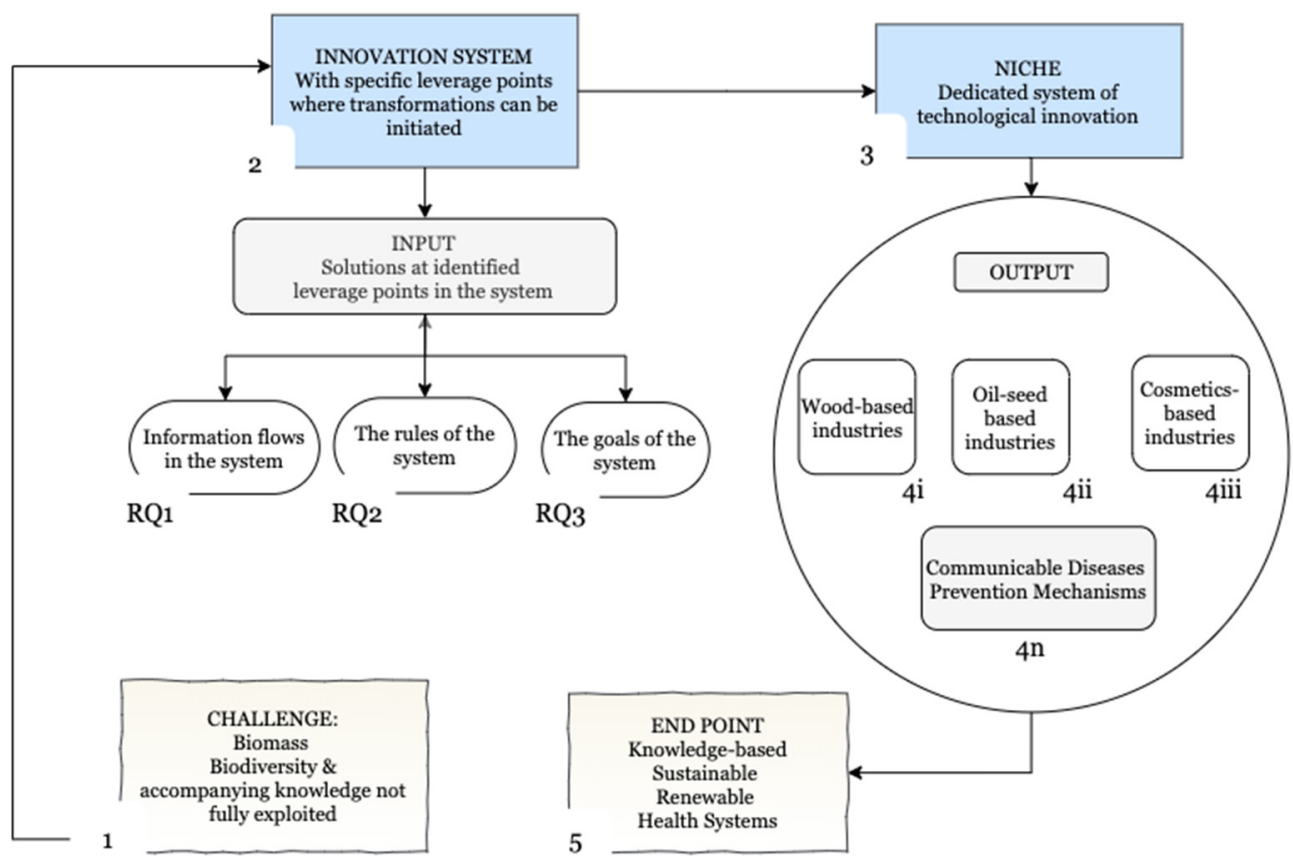

Figure 2. Conceptualisation of leverage points for a knowledge-based bioeconomy transition.

Firstly, to investigate the structure of information flows, we assess how the configurations of the knowledge base within the sampled firms affect the emergence of a sectoral knowledge-based health bioeconomy in Kenya. We expect this configuration to focus on several knowledge fields that are most lucrative for competing in a global knowledge-based health bioeconomy, such as the emerging biosynthesis landscape [16,17]. As established in the scientometric empirical analysis by Breschi and colleagues, even the most diversified firms often tend to become more coherent. They increase their knowledge coherence by systematically finding patent technological classes related to the classes with which they started, as they expand their activities and diversify their actions [18]. This may seem counterintuitive, but it provides the basis for increased specialisation, which is necessary for the emergence of a sectoral system of innovation.

The theoretical underpinning is based on the patterns of sectoral and technological change $[13,19]$ and system dynamics driven by cumulative and path-dependent processes [20], as demonstrated in the literature on the accumulation of technological capabilities in developing countries. This theory supports the notion of economies of scope in the "use of one body of knowledge", implying that the same type of knowledge can be used as an input in multiple technology or knowledge fields [21,22] due to common heuristics and scientific principles. Therefore, we ask what knowledge fields are interlinked to disease prevention mechanisms and explore their potential to influence the transition to a sectoral knowledge-based health bioeconomy in Kenya. We anticipate that the firms interviewed will highlight common and related knowledge fields as important for the transition to a knowledge-based health bioeconomy. These fields are likely to share common heuristics and scientific principles.

The structure of information flows as a leverage point is defined in [6] as "who does and does not have access to what kinds of information". This "new loop" refers to instances where information flows where it previously did not, causing the system to behave differently. To address the empirical gap on the determinants of knowledge 
diversification in the innovation ecosystem of preventive medicine in Kenya, we explore the determinants of diversification and the mechanisms that may enable increased knowledge diffusion given the dynamics between public versus private institutions in this ecosystem.

Our second objective looks at the rules of the system, asking how the strength of sociotechnical regime institutions impacts the expansion of disease prevention research and innovation activities. Even if developing economies gain access to cutting edge technologies through their diffusion, the question of whether they can use this knowledge and these technologies to diversify their products and become players in the global new bioeconomy like other developed countries remains [23]. In the United Nations Conference on Trade and Development (UNCTAD) Report, Juma and Konde propose four factors that would facilitate broader participation of developing countries in the new bioeconomy. The first factor is that current globalisation patterns include developing country products. As might be expected, this depends not only on their domestic technological capacity but also on the type of global bioeconomy governance systems that emerge from policy debates [23].

Juma and Konde's insights inform our analysis in this second investigation, in which we consider rules to be representative of the institutions responsible for firm selection and niche maturation in an innovation system [23]. These rules of a system have been proposed as an essential consideration in institutional literature [24,25] and defined as the incentives, punishments, and constraints in a system that determine its degrees of freedom [6]. For instance, [26] defines institutions as the formal and informal rules that organise social, political, and economic relations. Therefore, the configuration of institutions in the knowledge-based health bioeconomy will shed light on the associated governancerelated leverage points. As Meadows suggests, "if you want to understand the deepest malfunctions of a system, pay attention to the rules and who has power over them." [23].

Our research further recognises the empirical gap that it has not yet been established how firms' internal decision rules influence their perception of the "rules of the system". Nelson and Winter's primary assumption regarding the behaviour of firms addresses why firms do what they do, or what factors shape their decision making [13]. Attempting to respond to this gap, we consider that the performance objectives of these firms are unique. Therefore, their internal decision rules are responsible for variables that guide how they respond to the incentives, punishments, and constraints in the innovation system, i.e., the bioeconomy governance systems. This in turn impacts the achievement of their unique performance objectives within the innovation system [27]. Therefore, as a second objective, we explore the factors that shape the decision making of the sampled firms, the interaction between these factors, as well as the incentives, punishments, and constraints that affect the expansion of disease prevention research and innovation activities. Such incentives, penalties, and constraints are reflected in the extent to which the state controls innovation activities, imposes barriers to entrepreneurship, facilitates trade and investment, and engages in biodiversity conservation. Ivanova and Chatzouz explored these and investigated the effect of the "rules of the system", referred to in their study as "innovation policies" on sectoral productivity growth [28].

Our third objective is to explore the goals of the system, which often determine the general intent and outcome of system actors. For instance, genetic engineering is neither a bad nor a good tool. Its directionality depends on the goal of the actors using the technology [6]; the same is true for the exploitation of indigenous genetic resources, which are an advantage for a knowledge-based bioeconomy. The goals of the system reflect what the system does as a whole, as opposed to what anyone tells the actors in the system to do. Previously, we examined how a firm's internal decision rules impact its perception of the "rules of the system". However, regarding this third objective, we recognise that the decision rules of a firm cannot be summarised in the perspective of the firm's leader expressed in an interview, which is the methodological approach of this research. It would be essential to investigate the overall "goal of the system", defined by the general outcome of the actions taken by various actors as a leverage point, which Meadows describes as 
either survival, resilience, differentiation, or even evolution. We thus need to understand how the goals of the system can be measured [23].

Woolthuis and colleagues sought to clarify the application of the concept of systems failures to the theory of systems of innovation by drawing on literature to illustrate how these systems failures can be mapped in a mutually exclusive manner. This approach was intended to provide a framework for analysing policy actions to evaluate and explain the success of those policies within an innovation system. By defining these outcomes, the framework inadvertently communicates the general intentions and outcomes of its actors. Some of the exclusive systems failures listed include: infrastructural failures, transition failures, path-dependent failures, hard institutional failures, soft institutional failures, strong network failures, weak network failures, and capacity failures, attributed to system actors with heterogeneous profiles [14].

The observation that modern technical solutions, such as those in the knowledgebased health bioeconomy, are characterised by an increasing interrelatedness between heterogeneous actors and knowledge fields, causing firms to seek external knowledge sources within complex adaptive systems $[29,30]$ influences our third research objective. In such a heterogeneous complex adaptive system, systemic imperfections can occur when combinations of mechanisms do not function efficiently and present risk areas [29]. Potential risk areas include misalignment of institutional infrastructures or even structural connectedness [31].

In response to the empirical gap in understanding the overarching goal of the system within the knowledge-based health bioeconomy in Kenya, we employ the analysis of system failures. We examine how they nudge the development of our target system. As noted by Woolthuis and colleagues, these system failures are associated with risk areas [14]. Examining the risk areas linked to the desired system, i.e., the knowledge-based health bioeconomy, allows us to extract some of the system failures.

\section{Methodological Framework and Research Process}

Employing a qualitative approach, we use CLD to explore leverage points around the structure of information flows, the rules of the system, and the goals of the system that are involved in the feedbacks governing the transition to a knowledge-based bioeconomy in preventive medicine in Kenya.

\subsection{Causal Loop Diagrams as a Method}

Causal loop diagrams (CLDs) help to highlight the internal assumptions of the preventive medicine systems in Kenya and the associated leverage points for transitioning to a bioeconomy. CLDs are a qualitative systems conceptualisation tool employed in model building that provide a language to illustrate the dynamic interconnected nature of the world $[32,33]$. They are part of the general body of configurational theorising in the area of complex causality. In configuration theorising, tools are used to map multifaceted interdependencies, probe connections, and articulate orchestrating themes that support underlying coherence $[11,34,35]$. They contrast with correlational configurations and address the challenge of complex interdependencies associated with socio-economic issues. These complex interdependencies are often explained through multiple factors that highlight their outcome(s) of interest. Therefore, the goal of CLDs is primarily communication rather than simulation [11], as they serve as a foundation for qualitative scenario building, quantitative system dynamics models, and stakeholder engagement in policy planning. The approach complements work of Birch and colleagues [5], who used CLDs to explore dynamics linked to the agricultural sector in Sweden.

We generated the diagrams and interpretations presented in the next section using the Vensim ${ }^{\circledR}$ Software (Version 8.0.9). These diagrams and interpretations may not represent the entire real context and are only general representations. As explained earlier, summarising a firm's decision rules based on the perspective of their leader expressed in an interview is difficult. Given the participatory process, some causal factors or links may be missing 
due to missing data or participant representation. Some of the relations presented may not be causal.

\subsection{Sample Size and Data Sources}

We collected qualitative primary data through 16 semi-structured interviews with key informants using a mixture of purposive and theoretical sampling. This approach considered the four stakeholder groups involved in a knowledge-based health bioeconomy. In a 'snowballing' process, we conducted the interviews with selected individuals, including senior researchers, senior civil servants, research directors, pharmaceutical directors, and activists.

Participants needed to be thought leaders in their firms and the health bioeconomy domain. The selected firms are also considered competitive in the same field. After interviewing a participant, they often recommended another suitable interviewee to complement their responses and meet our research objectives. For instance, after interviewing the senior patent examiner due to his role in knowledge management, he recommended interviewing the Chief Executive Officer (CEO) of a leading health products regulation firm to ensure our research was substantive. Table 1 presents a list of interviewed profiles. We omitted details of their respective organisations for confidentiality.

Table 1. Participating Profiles.

Organisation Category

R\&D organisation or academic institution (research)

Private sector (biomass transformation)

Health practitioner (health system actor)

Government (regulation and support)
Position of Key Informant

Senior Lecturer Biochemistry Department

Medical Entomologist

Research Scientist-Biostatistics

Chief Scientist-Center for Biotechnology Research and Development (CBRD)

Group Head- Strategy, Business Development and Communications Good Manufacturing Practice, Quality Assurance Regional Manager Application Specialist-Molecular Biology Trade Advisor-Healthcare Physician and Global Health Specialist Co-Founder and CEO, Global Health Impact Investment and Social Entrepreneurship Chief Research Officer and Senior Clinical Trialist Programme Manager-International Development (Bioeconomy) Senior Patent Examiner-Biotechnology Industry Senior Biostatistician-Pharmaceutical Products Examination Chief Research Officer-Medical Knowledge Management Platform CEO-Health Products Regulation

We interviewed the participants about the health bioeconomy (see Appendix A for the general framework of the semi-structured interviews). The interview questions followed the three research objectives highlighted in the Introduction and Literature Review sections and included a preamble with questions related to the definitions of bioeconomy and preventive medicine.

The data collection process was iterative, as we referred to extant literature during the process, and participatory through repeated interviews with key informants. After an initial thematic analysis to highlight the variables of interest, we coded the transcripts in a qualitative analysis following grounded theory guidelines [36] in MAXQDA Analytics Pro (Release 20.2.2). We performed the thematic analysis using grounded theory guidelines to identify the most recurrent themes as the construction of pathways for system transition to a sectoral knowledge-based health bioeconomy in Kenya with trends from preventive medicine. The second iteration of the analysis provided the causations and associations which allowed us to construct the CLDs presented in Section 4 of this paper. 


\section{Results and Analysis}

Before presenting the identified causations linked to the feedback mechanisms in the complex adaptive system specific to preventive medicine in Kenya, we introduce the definitions of bioeconomy and preventive medicine in the practitioners' perspectives. This allows us to pave the way for the perceptions and causations drawn based on the three research questions addressed in this study.

\subsection{Perceptions of the Bioeconomy}

We conducted a keyword analysis based on the responses to the definition of a knowledge-based health bioeconomy. Some of the emergent keywords are knowledge, products, health, biological, economic, environment, improve, and sustainability. These keywords were mentioned with a frequency of $80 \%$ and above (see Figure 3 and Table 2).

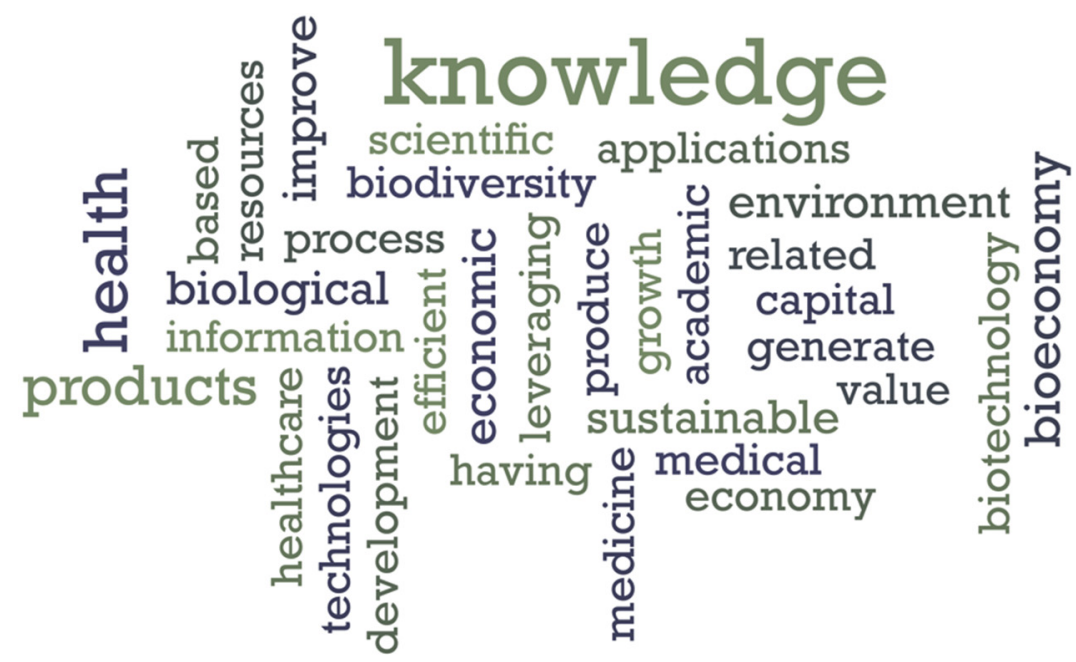

Figure 3. Word cloud representing the definitions of the concept of a knowledge-based health bioeconomy.

Table 2. Word frequency of the definitions of the concept of a knowledge-based health bioeconomy.

\begin{tabular}{cc}
\hline Word & Frequency \\
\hline knowledge & 7 \\
products & 5 \\
health & 4 \\
biological & 3 \\
economic & 3 \\
environment & 3 \\
improve & 3 \\
sustainable & 3 \\
\hline
\end{tabular}

The definitions provided describe the knowledge-based health bioeconomy as socioeconomic improvement through health, biotechnology, and medical applications, whether linked to the use of biologics or to sustainable environmental and biodiversity practices, all of which are considered forms of capital. These applications rely heavily on coded, tacit, and indigenous knowledge. The role of indigenous knowledge is applied to biodiversity exploitation and traditional medicine considerations. Hence, the significant role of knowledge management in building a knowledge-based health bioeconomy becomes apparent.

\subsection{Preventive Medicine and the Health Bioeconomy}

The participants confirmed that a knowledge-based health bioeconomy is indeed an existing notion in the practise of preventive medicine in Kenya. Table 3 outlines some 
of the actions taken in a knowledge-based bioeconomy as presented by the stakeholder groups interviewed.

Table 3. Actioning the knowledge-based health bioeconomy.

\begin{tabular}{ccc}
\hline Stakeholder Group & $\begin{array}{c}\text { Actions in the Knowledge-Based Health Bioeconomy } \\
\text { Applying the first principles of nature and traditional medicine to } \\
\text { conventional medicine. }\end{array}$ \\
R\&D organisation or academic institution (research) & $\begin{array}{c}\text { Managing knowledge emanating from research projects and } \\
\text { programmes, which principally leverages biological resources. This } \\
\text { knowledge is used to inform policy design, for instance on a change in } \\
\text { malaria prevention products due to resistance patterns in the population. } \\
\text { A demand-led approach of linking start-ups with academics so they can } \\
\text { access platforms offering lab infrastructure or clinical trials. } \\
\text { Linking academic scientists with industry players to develop concrete } \\
\text { products for industry. } \\
\text { Using biology to understand diseases and make new interventions. For } \\
\text { instance, through the regional biobank housed in the region, they } \\
\text { understand the genetic factors around the malaria parasite and use it to } \\
\text { design the next line of drugs and vaccines. }\end{array}$ \\
\hline
\end{tabular}

Improving the country's diagnostics fields by deploying and implementing technological interventions and innovations that improve the turnaround time of diagnosis. These interventions improve the rapidity of decision making by clinicians who know whether to admit a patient or not, eventually saving costs.

Promoting, marketing, and providing export markets for companies in a knowledge-based bioeconomy to expand their technology or sell their know-how.

Developing biological molecules with medical and manufacturing applications and developing the technologies for manufacturing.

Private sector (biomass transformation) Importantly, it does not just involve the development of biologics but also the value-addition processes in the ecosystem from R\&D to market consumption.

Developing therapeutics from product development to deployment to the health system, focusing on building their infrastructure, not as a physical space but leveraging networking capacity and platform use with global partners, hence as a virtual centre. Therefore, acting as a catalyst for product development for the bioeconomy. An example is the Indian

Open Platform for Product Development which does not rely on individuals living in India but using the Indian minds anywhere in the globe to feed into what they are doing in India.

Health practitioner (health system actor)

Strengthening the health system around maternal and child health, urbanisation, well-being, education and youth empowerment, the future of work and population health, especially in the ageing population.

Regulating the country's pharmaceutical and medical industry activities to improve the products on the markets and promote human health. The analysis of proposed products thus enables their conversion to marketable products.

Structuring the national industrial property infrastructure for the bioeconomy, especially with regard to the Convention on Biological Diversity (CBD) (1992) and the Trade-Related Aspects of Intellectual

Government/policymaker (regulation and support) Property Rights (TRIPS) Agreement (1994). The country has made some efforts regarding the first CBD objective on conservation. Advances have been made on objective two (sustainable utilisation of biodiversity) but much remains to be done before objective three, access and benefit sharing, will be achieved. By shaping the national infrastructure for industrial property, they will guide the development of the national bioeconomy. 
Prominent perspectives of the knowledge-based bioeconomy in preventive medicine can therefore be summarised in the following four areas:

1. Vaccine development: Considering that vaccines are essential to the discussions on preventive medicine, there is a need to develop vaccines relevant to the Kenyan population instead of just using those that have global significance. Simultaneously, there is a need to build capacity to develop these vaccines. One of the participants from the private sector argued, "There is already a strong business case for vaccine development, with Kenya having the potential to build a 200 million dollar-a-year industry, and in Africa from 1 to 2 billion. Vaccine development goes beyond being a niche and can be considered as an industry in and of itself".

2. Cost of preventive medicine: Preventive medicine is cheaper for the economy, so it is valuable to prioritise it in the bioeconomy. When entomologists study the transmission mechanisms of the malaria parasite, they seek to establish better control mechanisms, which translates into preventive medicine.

3. Nutrition and preventive medicine: Preventive medicine is often linked to natural products and nutritional patterns of a population. This association encourages organic agriculture and more wholesome nutrition habits. In addition, the benefits of medicinal plants are often maximised when the plant is used without purification. Their overall anti-inflammatory properties allow them to target a range of diseases, hence the need for bio-conservation.

4. Climate considerations: One of the most apparent practical applications for preventive medicine and the knowledge-based health bioeconomy is collaborating with climate scientists to understand how the climate (or climate change) affects disease trends, the drivers of these trends, and how to address them.

Based on these insights and employing grounded theory principles [36] we constructed pathways for system transitions to a sectoral knowledge-based health bioeconomy in Kenya (see Figure 2). A dominant storyline emerges with the central phenomenon of causality around four areas (see also Figure 4):

1. Government inertia: For instance, the current industrialisation strategy does not focus on innovation, but on export processing zones. Fiscal measures and nudge policies are needed to build the bioeconomy, e.g., policies that reduce risks associated with innovation. Such measures enable the emergence of an innovation system specifically focused on health.

2. Bio-conservation, coding, diffusion, and valorisation of indigenous knowledge around traditional medicine: This is related to the establishment of an environment conducive to promoting and protecting intellectual property rights for socio-economic development.

3. Building business models appropriate for both academia and the start-up industry.

4. Institutional change of focus from a curative standpoint to a more preventive framework for clinicians and health implementers.

Through this same analysis, the following proposed interventions emerge:

1. Designing public policy for the health bioeconomy will ensure that health care implementers directly leverage data from researchers with clear intersectoral guidelines and complementarities;

2. Redefining the concept of value in the medical industry with regard to traditional vs. conventional medicine will lead to increased use of genetic information to develop preventive therapies and interventions specific to the local population;

3. Addressing the business models for academia will foster a thriving local pharmamanufacturing ecosystem;

4. Increased adoption of knowledge-based health interventions designed by scientists will create efficient health systems that reduce the number of misdiagnoses and cases of misuse of medication as well as improve patient health outcomes.

In the next sections, we present the causations linked to the feedback mechanisms in a complex adaptive system specific to preventive medicine in Kenya. These are presented as 
specific leverage points around the structure of information flows, rules of the system, and goals of the system.

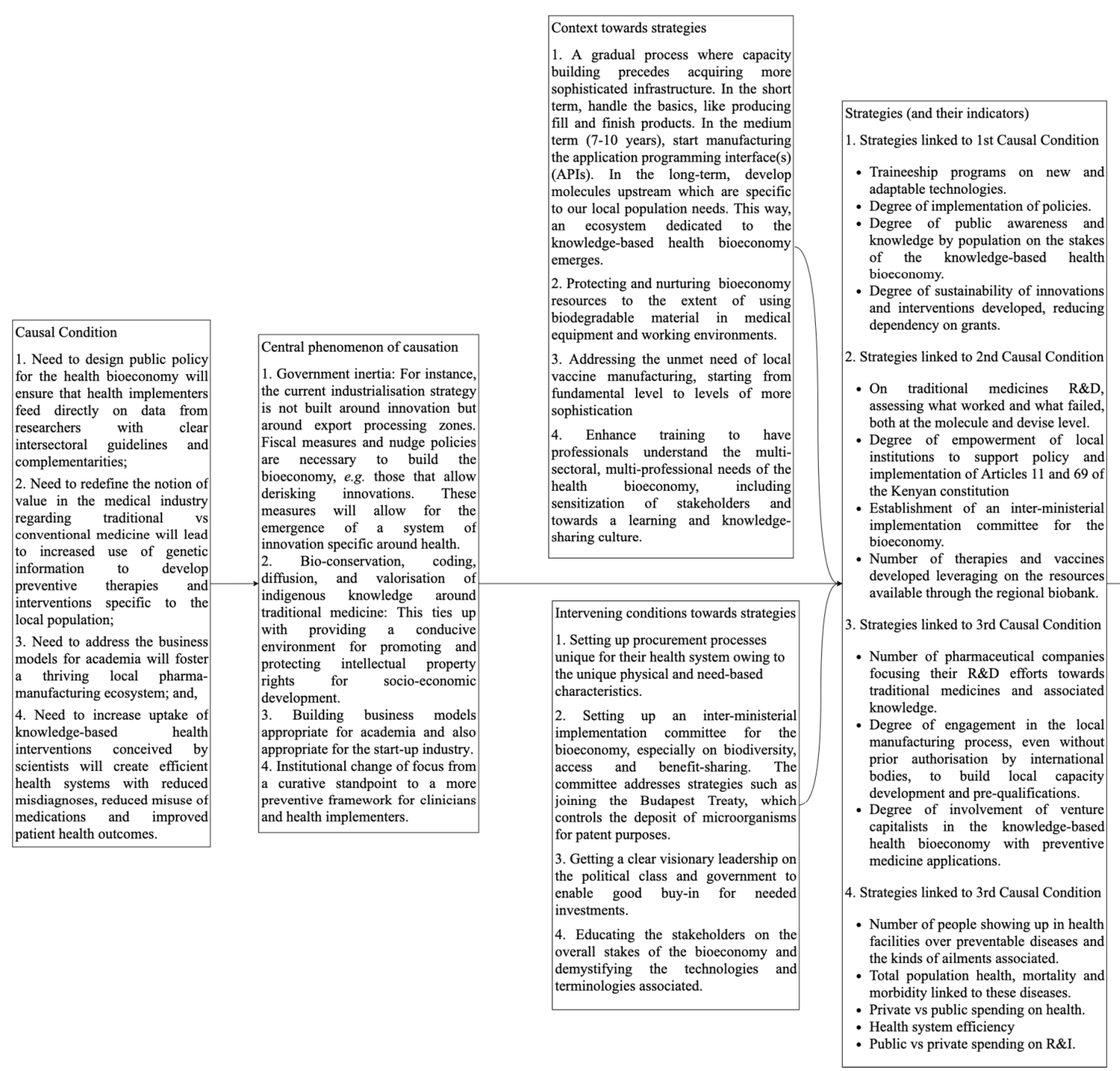

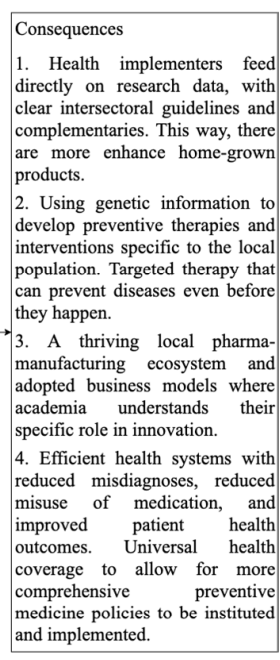

Figure 4. Constructions of pathways for system transitions to a sectoral knowledge-based health bioeconomy in Kenya with trends from preventive medicine.

\subsection{Structure of Information Flows}

Our findings show how the configuration of the knowledge base within the sampled firms affects the emergence of a sectoral knowledge-based health bioeconomy. Several loops can be derived from the overall CLD, as summarised at the end of this sub-section, with the outcome of interest being the degree of emergence of new knowledge domains necessary for a knowledge-based health bioeconomy. First, the "degree of understanding the responsibility of conducting research" leads to an increase in the "degree of crosscutting roles between public and private institutions", which in turn increases the "number and strength of public-private partnerships formed". There seems to be a perception that the role of conducting research is reserved for the public sector. One of the participants indicated that, by definition, most research should be conducted by public institutions. At the same time, another participant noted that, "public universities have the key role of knowledge generation." This reasoned argument seems to be a new emerging leverage point. If the responsibility for conducting research is also assigned to the private sector, this will affect the "number and strength of public-private partnerships formed". More public-private partnerships (PPPs) would imply an increase in the "number and strength 
of private institutions obtaining funds and participating in R\&D, i.e., knowledge-based industries". Consequently, more knowledge domains would emerge, which are necessary for a knowledge-based health bioeconomy (see Figure 5).

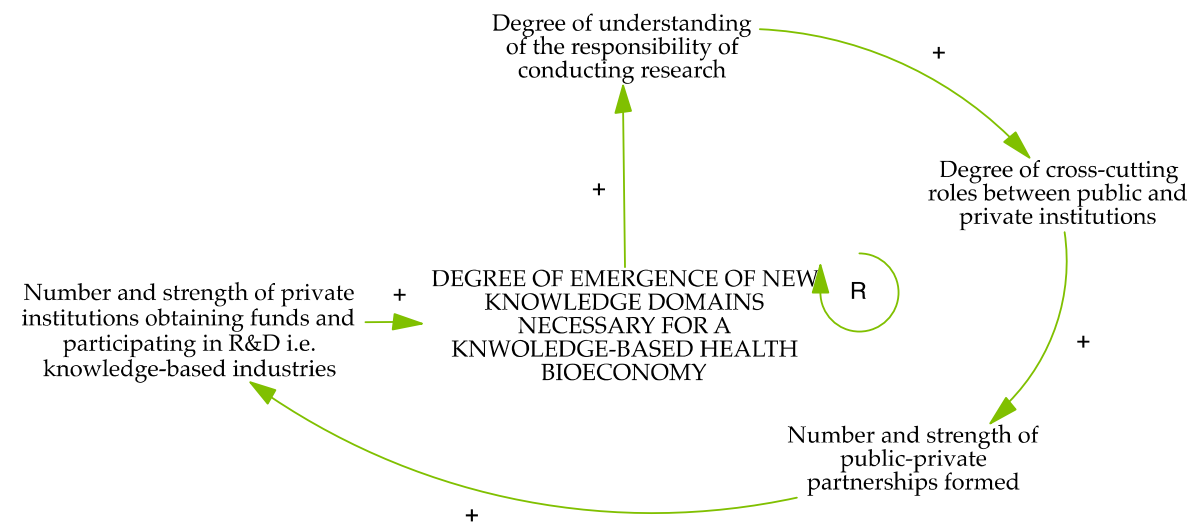

Figure 5. Technological diversification dynamics around the effect of knowledge diffusion in the creation of new knowledge domains for a knowledge-based health bioeconomy in Kenya.

Regarding public versus private firms' participation in research and innovation activities, an increase in the "number and strength of private institutions obtaining funds and participating in R\&D, i.e., knowledge-based industries" increases the "degree of technology transfer, i.e., conversion of information to knowledge to innovations". One of the private sector actors noted that funding organisations tend to favour partnerships with private over public institutions, especially when it comes to direct institutional funding rather than treasury funding. Partnerships are often formed between development partners and leading private hospitals in the region. While these are important initiatives for the country, it was recognised that services offered would have been more accessible and available to a larger group of people, rather than a selected elite, if the partnership had been formed with a public sector entity.

Enhanced technology transfer leads to an increase in the "number and strength of platforms generated allowing for communities of practice to exchange ideas across specific or diverse themes" and, consequently, in the "number and strength of public-private partnerships formed". This relationship positively affects the "ratio of problem-specific research conducted" and, as a result, the "ratio of cross-discipline and cross-domain models generated". The more diverse these models are, the more knowledge domains emerge, that are required for a knowledge-based health bioeconomy (see Figure 6).

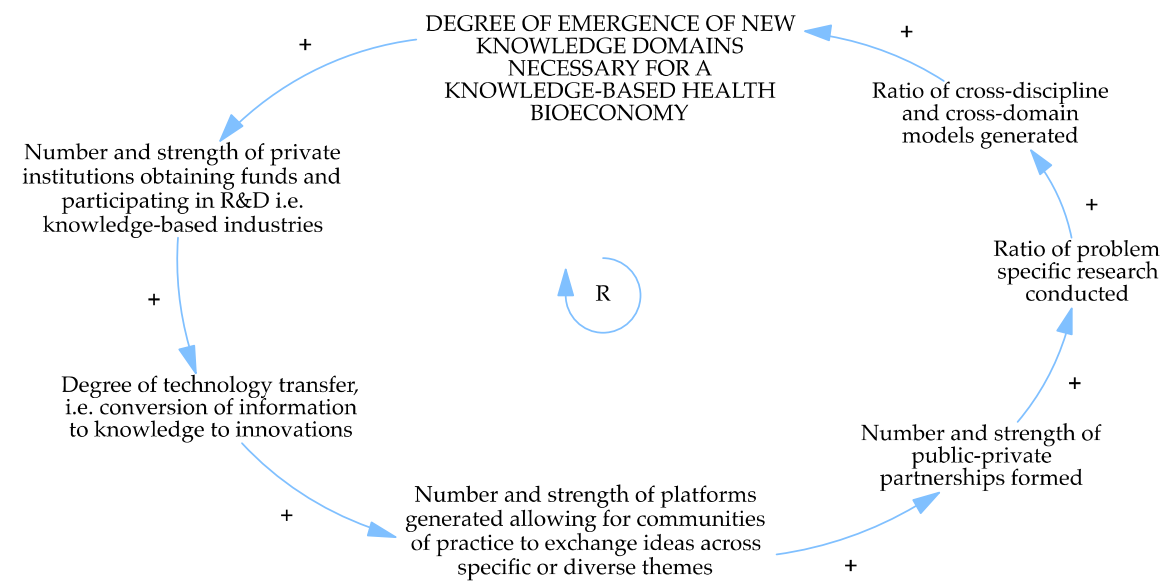

Figure 6. Public-private-partnerships in research and innovation dynamics around the effect of knowledge diffusion on the creation of new knowledge domains for a knowledge-based health bioeconomy in Kenya. 
Some of the knowledge fields that have proven useful and influential in creating domains needed for a knowledge-based health bioeconomy and that should be included as R\&D priorities are: ageing populations, artificial intelligence, bioinformatic applications in health, biosystems and bioengineering, biotechnology, diagnostics, healthcare management, home-based care, mental health, microbiomics, nutrigenics, obesity, protein extraction, proteomics, sociology of biotechnology acceptance, stem-cell technology, supply-chain management of health products, therapeutic, and vector ecology. Technology fields include diagnostics, e-health, manufacturing of pharmaceutical and medical devices, neonatal technologies, and vaccine development. Competences in basic research, knowledge management, and learning-based societies are also considered necessary.

Figure 7 below summarises the feedback loops and dynamics of the structure of information flows presented above.

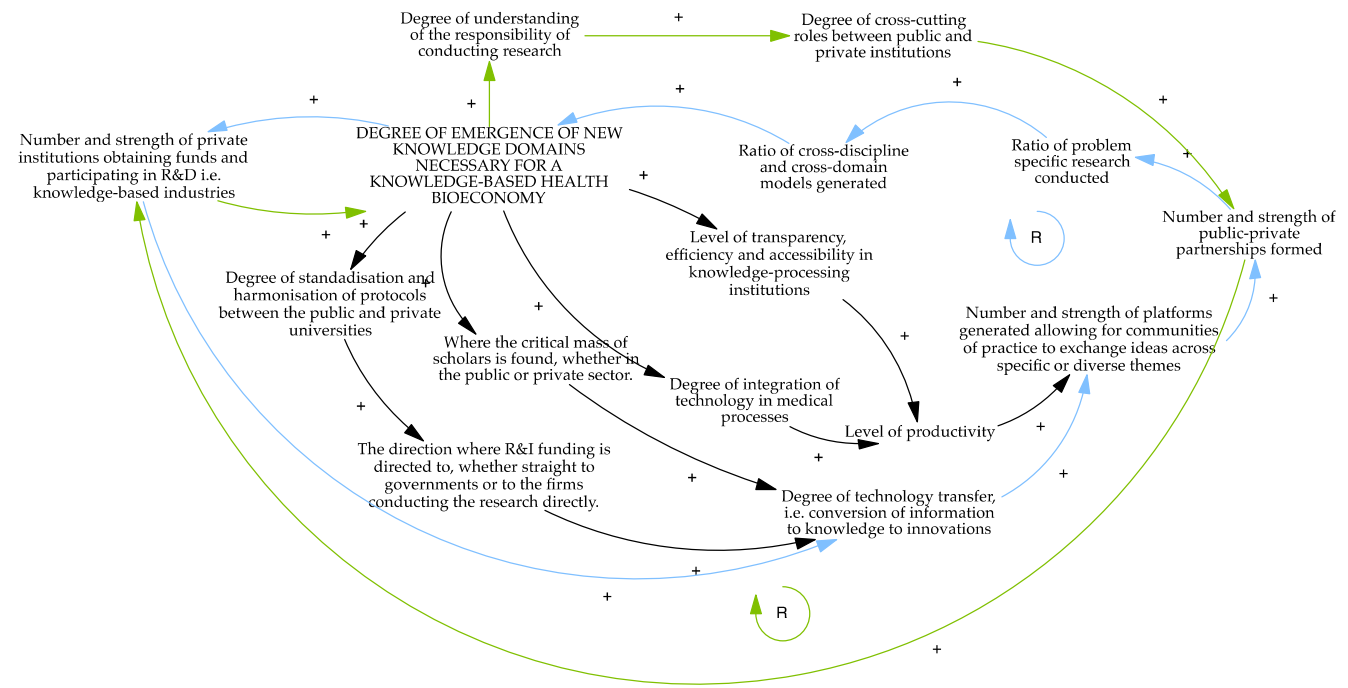

Figure 7. Dynamics of information flows in the creation of new knowledge domains for a knowledgebased health bioeconomy in Kenya.

\subsection{Rules of the System}

This section addresses how the strength of a socio-technical regime institution affects the expansion of disease prevention research and innovation activities. We hypothesise that the emergence of niches affects the development of radical or disruptive innovations.

Socio-technical systems theory argues that the main impediments to transitions are the need to overcome the rigidities and path-dependencies of existing, highly institutionalised system structures and to build new, more sustainable ones, as highlighted in the review of socio-technical regime institutions in the Australian urban water sector [24]. The regime-level consist of institutions and structures that reinforce socio-technical systems, whether individuals, firms, states, or social norms. The term "institutions" is understood from a neo-Schumpeterian perspective, where institutions are considered to dictate firm behaviour and the selection environment, leading to technological change [25], which we define in the context of regime-level entities in the multi-level framework. This definition recognises the co-evolutionary development of technologies, institutions, as well as social and economic subsystems.

Following the socio-technical regime paradigm, with respect to our second objective, we assume that the more lenient the institutions of the socio-technical regime, the easier it will be for firms to develop social and physical technologies that enhance niche emergence for a sectoral knowledge-based health bioeconomy in Kenya. More lenient institutions are less likely to foster path-dependency. As [24] points out, assessing a socio-technical system's semi-coherence and its regime is important to evaluate potential transition trajectories in a more detailed approach. Perceptions of this leniency of institutions were established 
through a self-assessment of surveyed firms, juxtaposed with the factors shaping their internal decision rules.

We identified several loops from the overall causal loop diagram, as summarised at the end of this sub-section, with the outcome of interest being expansion of disease prevention research and innovation activities. First, a dominant loop derived from responses from academia and research institutions shows that the higher the "amount of funding raised for research activities", the higher the "number of publications"; this in turn increases the "access to data and knowledge platforms". Increased access drives an increase in the "degree of data centralisation" through institutions such as the KEMRI knowledge centre. The focus of this knowledge centre's mandate is advocacy. This explains why the expansion of their actions would lead to an increase in the "extent to which the evidence from their research has been incorporated into decision making". More evidence-based decision-making increases the "availability of critical skills for technological advancement", meaning that human capacity exists to enable "increased technological improvements and their accessibility to populations". These technologies may achieve the most pervasive patent, leading to an increase in the "impact on population health outcomes" by research and academia. Increased impact means that they have "relevance in the biotechnological world/ perceived strength of the socio-technical regime institutions" and political buyin. Such buy-in will enhance "transparency in issuance of ethical, research and industry permissions", which can only be hindered by "poor governance" structures and practices. This effect will significantly impact on whether or not interventions such as "promoting local vaccine manufacturing" are successful, and consequently whether or not there is "expansion of disease prevention research and innovation activities" (see Figure 8).

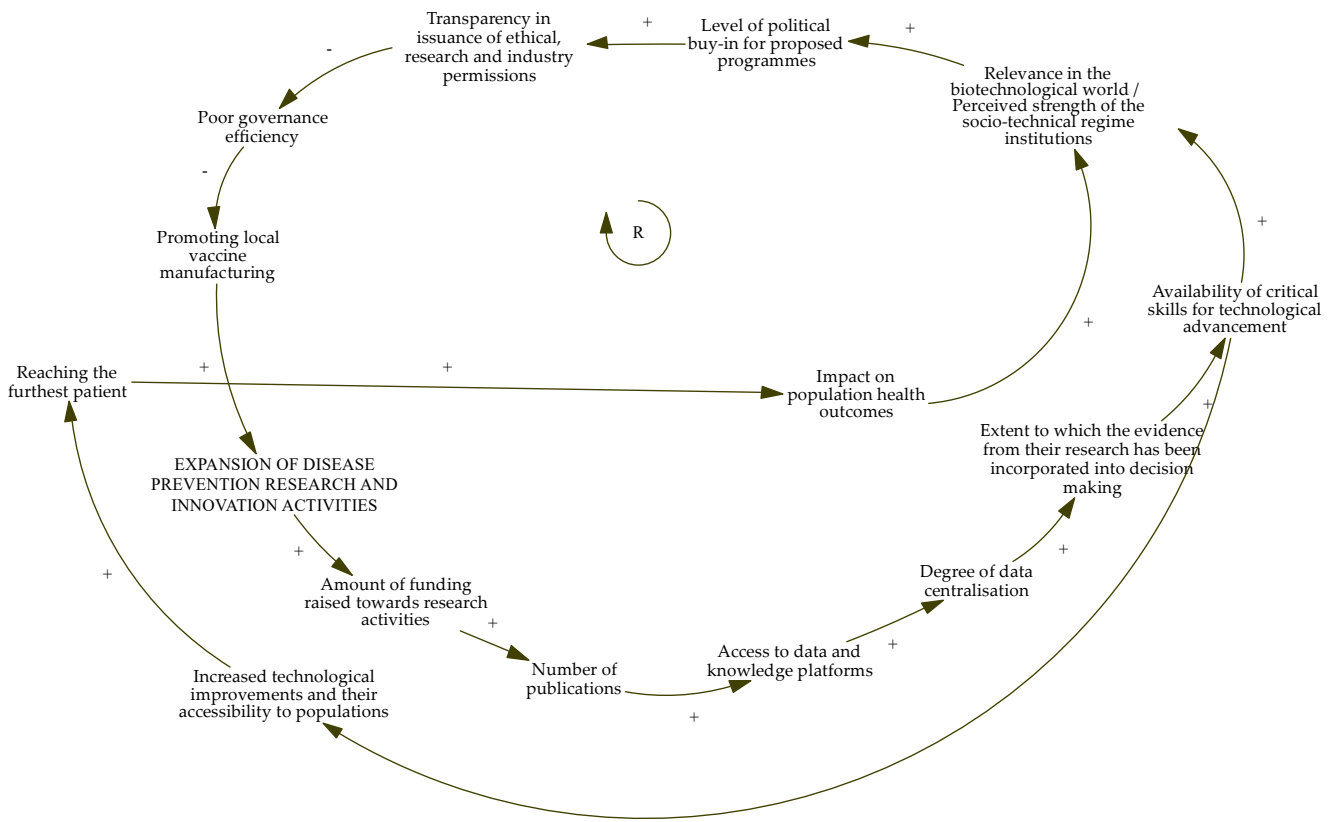

Figure 8. Academia and research institution dynamics around the effect of socio-technical regime institutions on the expansion of disease prevention research and innovation activities in Kenya.

Second, a loop concerning the actions of private firms seems to be strongly interlinked with a government services causal loop. Private firms are primarily responsible for "promoting local vaccine manufacturing", an activity that, along with bio-conversation, is central to the perception of promoting the health bioeconomy in the country. The "quality of service delivery to citizenry" determines whether the government can effectively engage in "creating an environment for the promotion and protection of industrial property rights for socio-economic development" which, consequently, affects the "extent to which the evidence from their research has been incorporated into decision making". The more advanced the evidence-based policies, the lower the "perceived public institution inertia". 
Inertia, however, would mean that there is a "multiplicity of regulatory institutions" which enable "bureaucracies within institutions leading to institutional inertia" and an increase in "time taken to obtain the necessary authorisations" by private firms. Coupled with "poor governance", this means a delay in "promoting local vaccine manufacturing", a phenomenon repeatedly experienced by the respondent private firms (see Figure 9). As one of the participants from a private pharmaceutical company said,

"In my mind, in an environment like ours in Kenya and to a large extent Africa, we have routine vaccines for medicines that are internationally important (polio, rotavirus, $H P V)$. These vaccines are as relevant to Africa as they are relevant to France, and therefore, they are made available. So, you find that these vaccines are only developed and manufactured by Western companies, and currently, to some extent, Asian countries. There is almost none of that in Africa. It means two things. (A) We have vaccines that the antigens themselves may not be very relevant to us or may not work perfectly for us because they are designed and developed for other environments. (B) We do not have vaccines for diseases that are only relevant to us. Therefore, we are unable to prevent preventable diseases because we do not develop our vaccines. From a system transformational perspective, we are only doing what other regions are doing for us. We cannot develop our preventive medicines!"

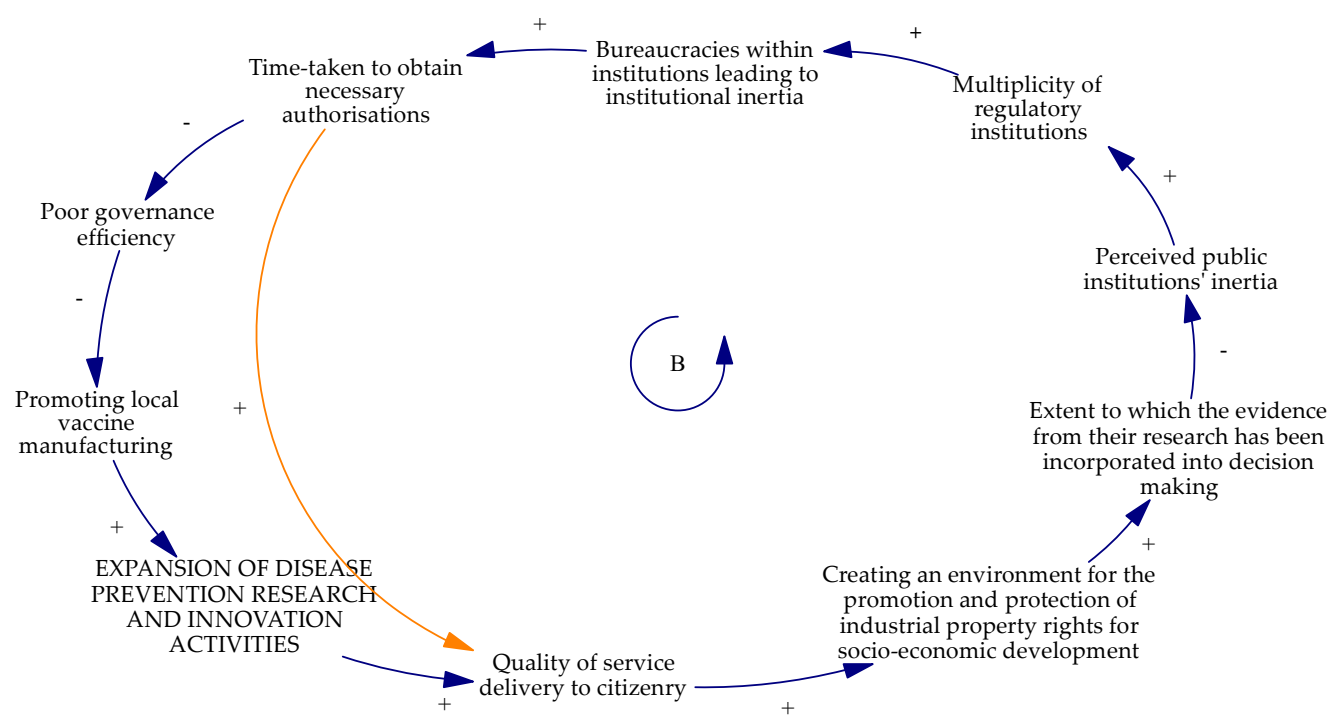

Figure 9. Private sector and government dynamics around the effect of socio-technical regime institutions on the expansion of disease prevention research and innovation activities in Kenya.

Third, health practitioners are interested in first "obtaining data from clinical trials to support registration of products", which then fosters "creating frameworks for capacity building, both human and infrastructural". In this way, they are "promoting local vaccine manufacturing", which ultimately leads to the "expansion of disease prevention research and innovation activities" (see Figure 10).

While obtaining data may be challenging for some health practitioners, there are no specific rigidities associated with the causal loop identified.

The feedback loops identified are crucial as they are responsible for the selection of innovative firms. Firms that can bypass institutional hurdles, such as turn-around time in service delivery and transparency in regulatory interventions, will be more successful. There seems to be reduced leniency in these two areas.

Figure 11 below summarises the feedback loops and dynamics of rules of the system presented above. 


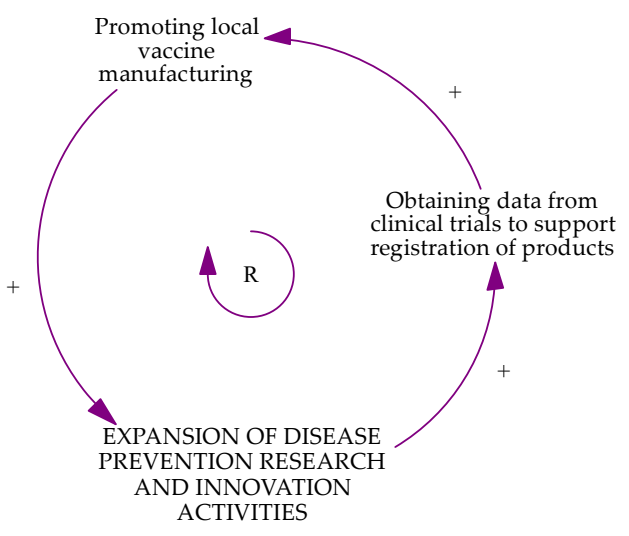

Figure 10. Health practitioner dynamics around the effect of socio-technical regime institutions on the expansion of disease prevention research and innovation activities in Kenya.

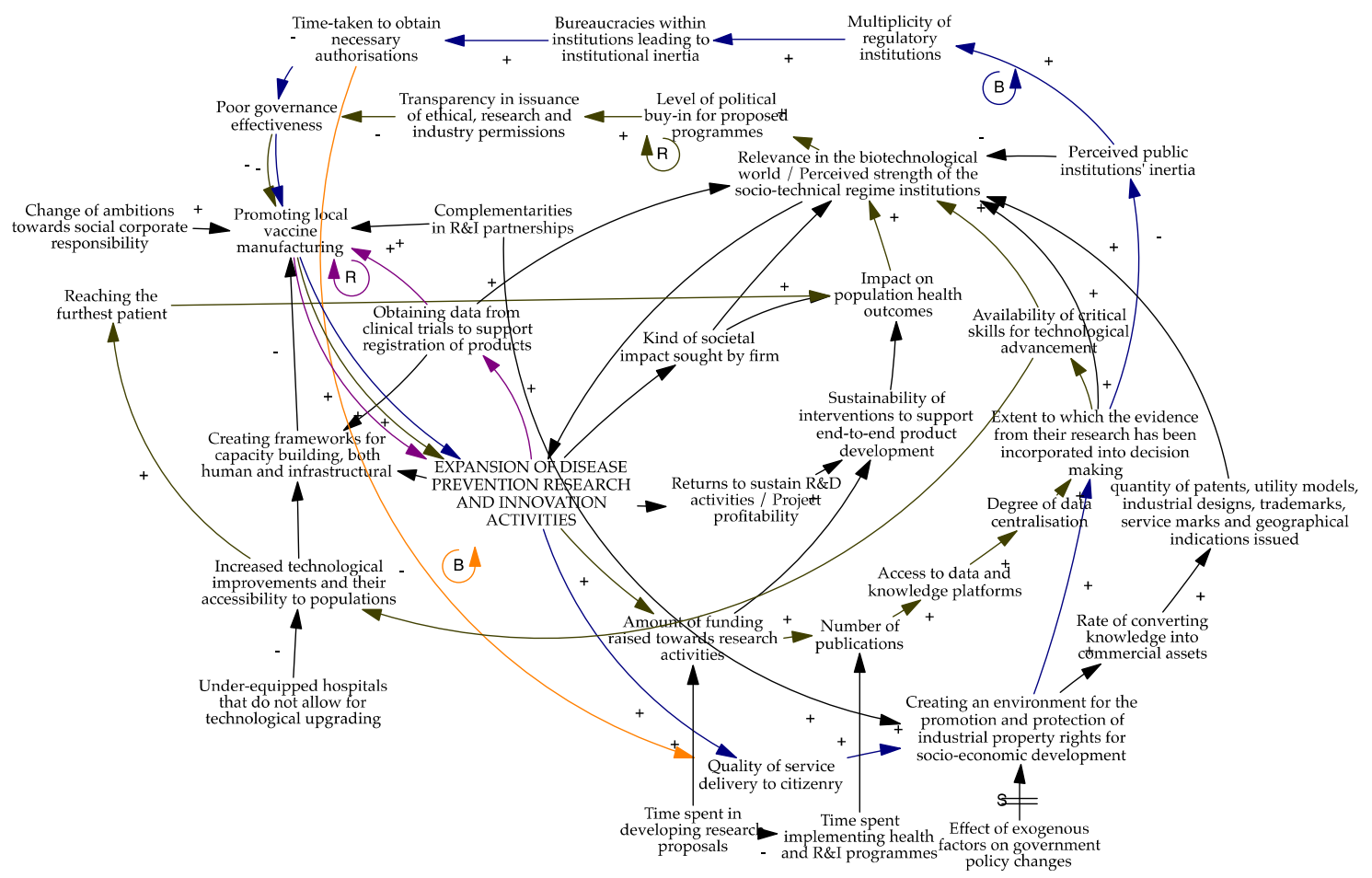

Figure 11. Dynamics around the impact of socio-technical regime institutions on the expansion of disease prevention research and innovation activities in Kenya.

\subsection{Goals of the System}

This section focuses on how systems failures in Kenya nudge a socio-technical regime towards a knowledge-based health bioeconomy. Our objective was to use a configurational theorising approach to reveal the risk areas in the innovation system as expressed by research participants. In this way, the inherent system failures as well as the general intentions and outcomes of its actors ought to be revealed.

We employed the Woolthuis framework for systems failures in innovation policy design to categorise prominent systems failures unique to the knowledge-based health bioeconomy in Kenya. We focus on the weak institutional failures that emerged from our analysis. This type of system failure includes the lack of linkages between actors due to low complementarities.

From the perspective of private sector demand factors, these failures are manifested when payment plans are not respected in the acquisition of technologies such as diagnostics. 
Public health institutions, for instance, negotiated payment plans with private international firms to acquire equipment, but did not adhere to the previously agreed payment dates.

As for knowledge institutions, these failures are manifested in academia's failure to understand its role in the knowledge economy, making it difficult to predict and anticipate what would happen in the health system. For instance, some universities sought to establish innovation incubators geared towards commercialisation, whereas their role in innovation should be invention, as one of the participants argued. This focus prevents them from realizing their full potential, which weakens the overall innovation system.

We observed a misspecifications and a structural disconnection between governmentrelated institutions that should be working together. For instance, in the management of indigenous knowledge and genetic resources, there is a need for a legal regulation that allows the Kenya Industrial Property Institute (KIPI) to track technologies and genetically modified systems and to take required interventions when withdrawals are necessary, such as in case of unethical use of genetic resources. In these circumstances, KIPI should work directly with other research institutions in the country, whether local or international.

Overall, weak network failures are evident in the difficulty of establishing causations. Good research is conducted by academia and research institutions, but implementing agencies are not aware of these processes, entities work in silos assuming ideas are not cross-cutting, and ideas are implemented without full stakeholder involvement. For example, sub-national government hospitals are supplied with equipment but lack the technical know-how to use it [37,38].

Our focus on weak network failures allowed us to draw several causal loops, as summarised at the end of this sub-section, with the outcome of interest being the "strength of complementarities or actors within the system". A first association appears when "considerations for the bioeconomy together with other sectors" increase. Here, the bioeconomy, and by extension the health bioeconomy, are considered only as drivers for the economy. We cannot consider the bioeconomy as an industry in and of itself. If we follow this perspective, in which the health bioeconomy is a part of a larger economy, one of the most important actions is to ratify important international treaties that enable intersectoral coordination. The interviewees highlight the Budapest Treaty (1977) as important, which requires parties to recognize microorganisms deposited as part of the patent procedure, irrespective of where the depository authority is located [39]. Participants argued that this policy move will break institutional silos by demanding research institutions to work more directly with the industrial property institute, and among themselves, to coordinate patenting of microorganisms used in their research.

Ratification of this treaty will "ensure inclusivity because the more inclusive you are, the less risks there are." This inclusiveness is demonstrated, for example, by KIPI collaborating with local and international research organisations and by protecting local biodiversity. This cooperation can further motivate and enhance the "set up instruments that encourage collaboration", e.g., funders can impose conditions in favour of collaborative proposals in their calls for proposals. The clarity achieved on the system's roles and synchronicity will ensure "improved regulatory capacities" in the system. Eventually, these actions strengthen the system complementarities (see Figure 12).

Secondly, in connection with the previous causal loop, we observed that there may be "misspecified institutions". In this case, the policy and institutional frameworks are already in place, but key linkages are missing. For one reason or another (including lack of infrastructure, leadership, adequate operating budgets, and support for emerging priorities), these institutions are unable to fulfil their mandate, resulting in functional deficits of the system. For instance, a biosciences policy was proposed, but has been revised several times in the past as debates on biotechnology, bioscience, health, information technology, and how to link these areas have not yielded results. Participants proposed to "set-up an intergovernmental-interministerial committee for the implementation of the bioeconomy" to deal with governance issues. In the interest of the health bioeconomy, this instrument will result in an "increased operationalisation of the Alma-Ata Declaration" in 
which traditional medicine is made a part of public healthcare [1]. Eventually, this will increase the "strength of complementarities of actors within the system." This cooperation can further motivate and enhance the "set up of instruments that encourage collaboration" (see Figure 13).

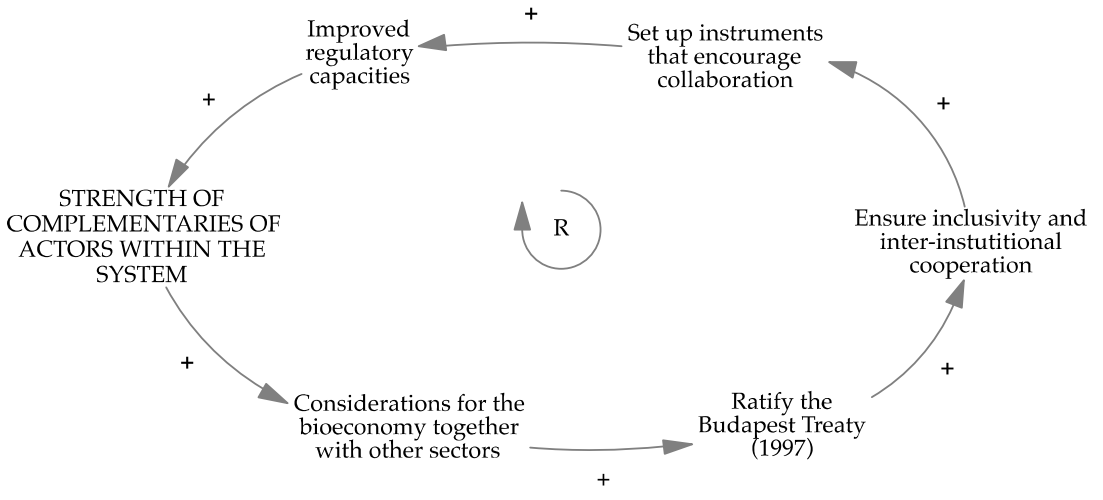

Figure 12. System dynamics around the effect of systems failures on the development of a sociotechnical regime in a knowledge-based health bioeconomy towards a dedicated system of technological innovation in Kenya.

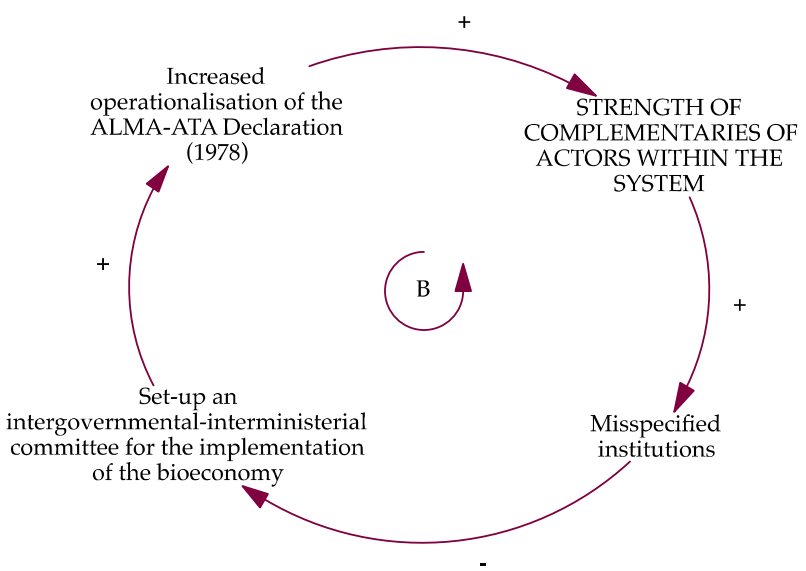

Figure 13. Government/policymaker dynamics around the effect of systems failures on the development of a socio-technical regime in a knowledge-based health bioeconomy towards a dedicated system of technological innovation in Kenya.

Thirdly, with respect to the private sector, the "rate at which payments plans are respected" would affect the perspectives toward the "formation of public-private partnerships". This cooperation, in turn, leads to an "increase in public-private sector collaborations", increasing the "strength of complementarities of actors within the system" (see Figure 14).

Regarding academic stakeholder interests, key informants perceived "defined roles of actors in the health innovation system" would enable "defined leadership to reduce the level of siloed work by system actors". Increased attention needs to be paid towards "training, sensitisation, leveraging champions", as without sensitisation, uptake of generated knowledge can be challenging. Increased sensitisation leads to a "reduction in the cost of maintaining the health systems" and "increased health population outcomes", i.e., a productive population that contributes to the "strength of complementarities of actors within the system" (see Figure 15).

Figure 16 below summarises the feedback loops and dynamics of goals of the system presented above.

After outlining the emergent CLDs, we discuss the leverage points identified in the next section. 


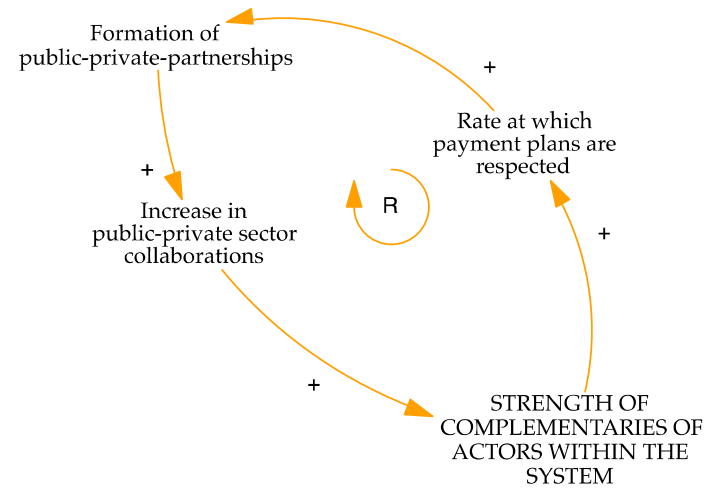

Figure 14. Private sector dynamics around the effect of systems failures on the development of a socio-technical regime in a knowledge-based health bioeconomy towards a dedicated system of technological innovation in Kenya.

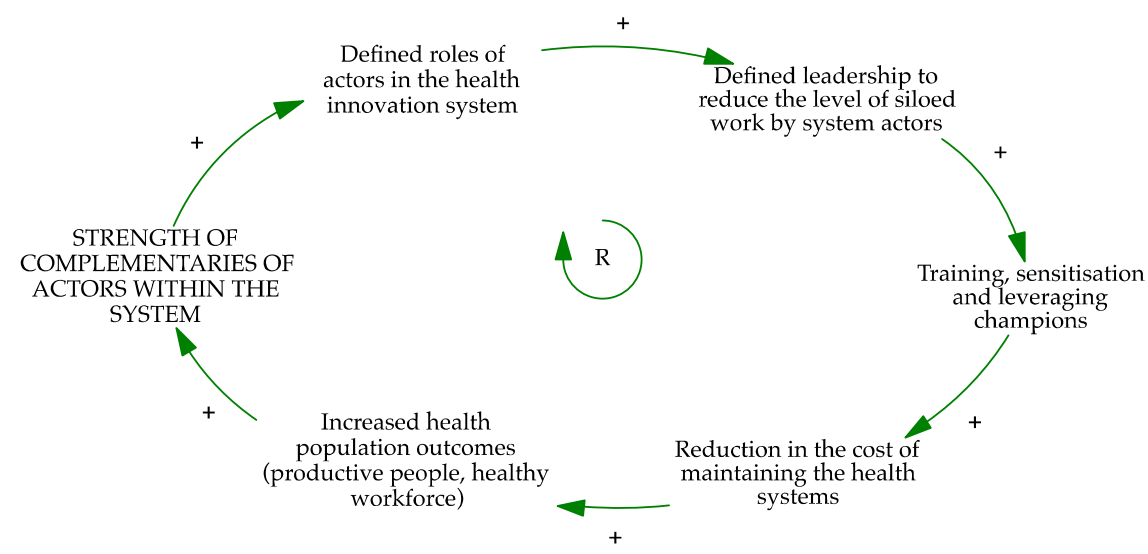

Figure 15. The dynamics of academia around the effect of systems failures on the development of a socio-technical regime in a knowledge-based health bioeconomy towards a dedicated system of technological innovation in Kenya.

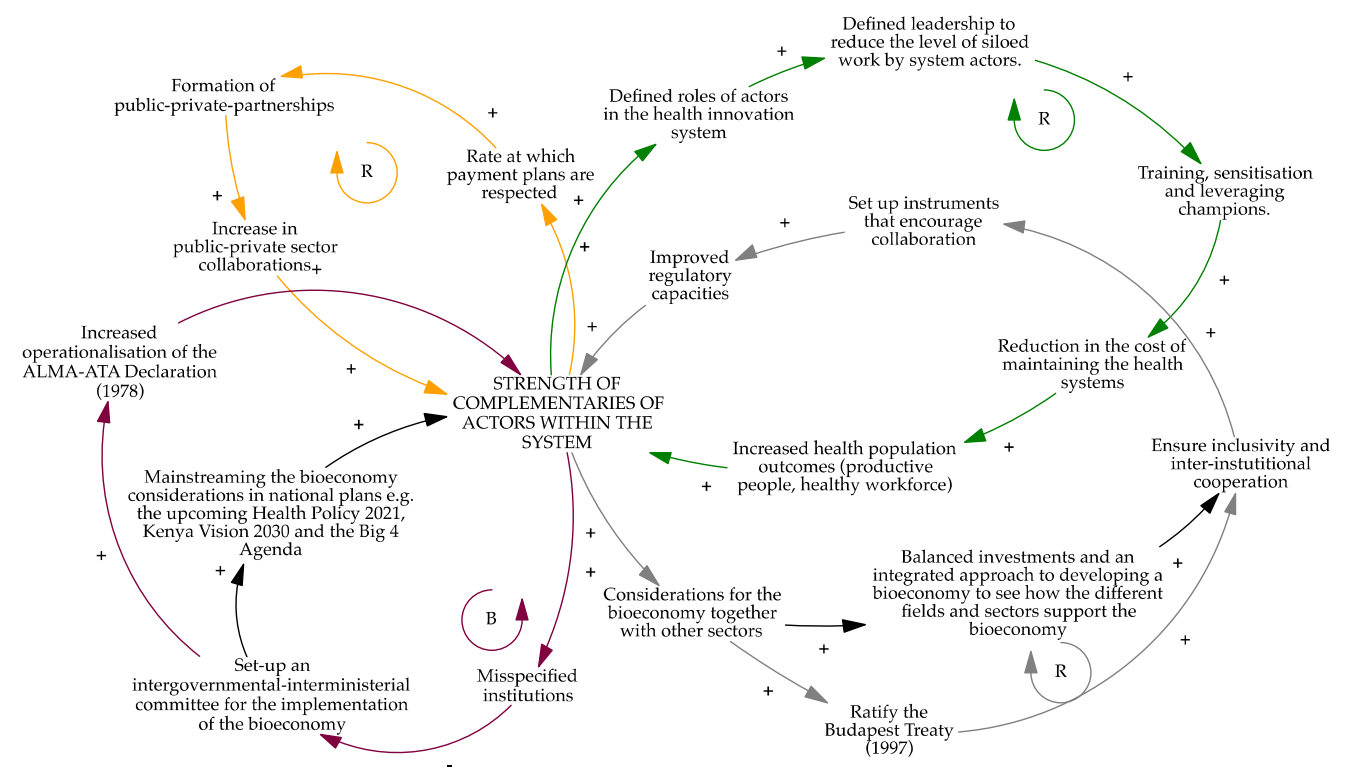

Figure 16. Dynamics around the impact of systems failures on the development of a socio-technical regime in a knowledge-based health bioeconomy towards a dedicated system of technological innovation in Kenya. 


\section{Transition Pathways towards a Knowledge-Based Health Bioeconomy}

The ideas of the knowledge-based bioeconomy outlined in this paper align with those proposed by global knowledge networks such as the Global Bioeconomy Summit, that define bioeconomy as "the production, utilisation and conservation of biological resources, including related knowledge, science, technology and innovation to provide information, products, processes and services in all economic sectors aiming towards a sustainable economy." [40]. The discussions focus on activities in health, biotechnology, and medical applications. This confirms that health is indeed an integral part of the bioeconomy, given the intersection between the use of biologics and sustainable environmental and biodiversity practices [41,42].

Regarding practical applications of preventive medicine, interviewees identified the development of local vaccine as a central need. Designing public policy for the health bioeconomy, redefining values, addressing the business models of system actors, and increasing the acceptance of knowledge-based health interventions are starting points for addressing causalities specific to preventive medicine in Kenya.

As for the first leverage point examined on the structure of information flows in the system, as shown in the results, knowledge diffusion appears to be decoupled between public and private institutions. In our case, there is an overriding perception that research is the domain of public research and academic institutions. This notion could potentially explain the reduced number and strength of private institutions obtaining funding and participating in R\&D activities. This finding aligns with international trends observed Arora and colleagues where larger (better-known) firms tend to invest in patentable technical knowledge rather than scientific research $[43,44]$.

The knowledge domains necessary for a competitive knowledge-based health bioeconomy are: ageing population, artificial intelligence, applications of bioinformatics in healthcare, biosystems and bioengineering, biotechnology, diagnostics, healthcare management, home-based care, mental health, microbiomics, nutrigenics, obesity, protein extraction, proteomics, sociology of biotechnology acceptance, stem-cell technology, supply-chain management of health products, therapeutic, and vector ecology. Further scientometric analyses would determine the degree of relatedness between the knowledge-outputs of the sectoral system of innovation. If there is convergence between the knowledge fields highlighted, this would lead to enhanced innovation in the technology areas of diagnostics, e-health, manufacturing of pharmaceutical and medical devices, neonatal technologies, and vaccine development. Competencies in fundamental research, knowledge management, and learning-based societies are also necessary.

As for the second leverage point examined on the rules of the system, the assumption regarding the behaviour of firms deals with factors shaping their decision making. We investigated the factors that influence firms' decision making and elicited how this affects their perception of the rules of the system, basing our conceptual framework on institutions to assess the socio-technical system's semi-coherence and its regimes. The feedback loops generated show that the firms' behaviour is strongly interconnected and semi-coherent. For instance, the amount of funding available to research firms (a decision-shaping factor) affects how they contribute to knowledge generation, which has an impact on the relevance they gain in the biotechnology domain. However, poor governance, as measured by government effectiveness in terms of the quality of bureaucracy and institutional effectiveness, is a critical leverage point in the system that can alter overall performance, impacting the public-service turnaround time, transparency, and regulatory interventions [45].

Finally, for the third leverage point examined on the goals of the system, system failures beyond incentive-based firm behaviour were extended to investigate other system failures influencing firm behaviour. We elaborated on more comprehensive, processoriented reasoning. Our findings indicate that incentive-based motivations are supported by more profound influences on firm behaviour, such as the need for environmental conversation, socio-economic development, fair-trade, respect for indigenous knowledge, and human and infrastructural capacity building [31]. This complements the findings of an empirical study in Korea, where environmental uncertainty, proxied by the average 
growth in the industry, number of competition, and instability of sales in the industry, has a significant mediating effect on managers' entrepreneurial orientation towards R\&D investments [46]. Referring to the Woolthuis systems failure framework [14], weak network failures were found to be the predominant system failure affecting knowledge diffusion. A lack of structural connectedness or complementarity among network actors prevents such networks from playing their 'catalyst' role for inter-organisational learning, which restricts transfer of information and knowledge over long distances [31].

Several solutions can be proposed to address these weak network failures, including adopting new perspectives that leverage open innovation to develop new business models. Yun and colleagues propose several models to make 'new' business models in a knowledgebased economy. They propose that these new approaches can focus the customer, user, social-entrepreneurship, or even the engineer open innovation-based business models [47]. Just as an example, engineering open-innovation based approaches would seek to identify the knowledge management approaches employed in the different institutions to optimise a systems-level knowledge-management framework, thereby addressing the questions of complementarities. Therefore, further in-depth analyses could identify the functional deficits caused by such network failures and model more effective policy interventions as well as new entrepreneurial strategies for open innovation.

\section{Conclusions and Future Research}

This paper sought to understand the feedback dynamics associated with Kenya's preventive medicine research and innovation as well as its contribution to a knowledgebased health bioeconomy. Sectoral development underpins the emergence of desirable features of the system. These include the expansion of disease prevention research and innovation activities, the emergence of new knowledge domains necessary for a health bioeconomy, and strong complementarities among system actors.

Many connections exit among the three leverage points explored in this research. Highlighting these leverage points is the first step in identifying policy measures for a systemic bioeconomy transition. This research offers practical value for designing policy interventions in this system. Subsequent research could involve the quantitative examination of the causal loops we identified.

Positive feedback loops can be observed in the following cases: First, regarding the structure of information flows, sharing the responsibility of research between public and private sector actors can enhance technological diversification. Second, regarding the rules of the systems, we observe a positive feedback loop between health practitioners' access to data for clinical trials and their contribution to the production of vaccine. Third, concerning the complementarities of system actors, positive feedback loops emerge for private sector actors and academia dynamics. We conclude that actions within the positive feedback loops, if activated, can promote the proliferation of business activities within the health bioeconomy. Further quantitative empirical research may reveal the threshold for activating system transformations.

Negative feedback loops are evident in issues of transparency in research, governance, turnaround-time for government processes, and leveraging research to support policymaking. Targeted nudge policies could be proposed, and further research conducted to better understand the reasons for inertia related to these leverage points.

Author Contributions: Conceptualisation, R.O. and A.P.; methodology, R.O.; formal analysis, R.O.; investigation, R.O.; data curation, R.O. writing-original draft preparation, R.O.; writing-review and editing, R.O., A.P.; visualization, R.O.; funding acquisition, R.O. and A.P. All authors have read and agreed to the published version of the manuscript.

Funding: This research was funded in part through a doctoral studies scholarship from the French government.

Institutional Review Board Statement: Not applicable. 
Informed Consent Statement: Informed consent was obtained from all key informants involved in the study.

Data Availability Statement: The data presented in this study are available on request from the corresponding author. The data are not publicly available due to privacy or participants.

Acknowledgments: We acknowledge supervisory support from Thierry Burger-Helmchen (Université de Strasbourg) and Robert Mudida (Central Bank of Kenya). We also acknowledge Emmanuel Kidiga (MBChB) for editing support, Lea Stöber (Hohenheim University Stuttgart) and Sarah Chauvin for preparing the final manuscript.

Conflicts of Interest: The authors declare no conflict of interest. The work was carried out with financial support from the French Government through the French Embassy in Kenya under a PhD scholarship grant.

\section{Appendix A}

General Framework of Semi-Structured Questionnaire

Questions posed through the semi-structured key informant interviews were as below:

A. Welcoming and gathering of participant information

1. Introduction to the research project, researcher background, research process.

2. Tell me about your background and your current position?

3. Are you already familiar with the knowledge-based bioeconomy concept? How would you define a knowledge-based bioeconomy/how do you understand the concept?

4. In what ways do you/your organisation/employer work with a knowledgebased bioeconomy?

B. Preventive medicine as a transition pathway to a sectoral knowledge-based health bioeconomy

1. Can you describe a desirable development that would follow from a transition to a sectoral knowledge-based health bioeconomy in Kenya? What is the desired change that a transition would bring (short term/long term)?

2. What indicators could be used to trace/measure this development?

3. Can you give examples of actions or proposals to implement to facilitate a transition process?

4. What are the main challenges to overcome in order to facilitate a transition process?

5. Can you come to think of any unintended consequences following a transition process?

C. Knowledge base (knowledge interactions and diffusion)

1. What knowledge fields interlinked with disease prevention mechanisms do you think are potentially relevant for the transition to a sectoral knowledge-based health bioeconomy in Kenya?

2. What are your ambitions for technological diversification? What drives this ambition for diversification?

3. How can systems be designed in the desired knowledge-based bioeconomy such that knowledge diffusion in the field is intensified? What frontier technology fields should be ranked as R\&D priorities for the next five (5) years?

4. In knowledge-based industries, new knowledge is more likely to emerge from the science sector, i.e., from public universities and public research institutions. What are your comments on this?

D. Institutions and niche emergence

1. What are some of the key factors that shape your decision making? Based on your day-to-day activities, what does profitability mean for you as a firm?

2. Have you experienced any institution-related barriers in the last five years in your research and innovation activities? Which are these? What institutions are most implicated in your research and innovation activities? 
3. Have you experienced any institution-related barriers in the last five years in your trade and investment activities? Which are these? What institutions are most implicated in your trade and investment activities?

E. Transdisciplinary innovation processes to include network of diverse stakeholderssystem failure and bioeconomy transition

1. Can you give examples of uncertainties or areas of risk linked to a transition process?

2. What measures could reduce this uncertainty/risk?

3. What actors should take lead in the transition process?

4. Can you give examples of actors or perspectives relevant to the bio-based economy, but currently being overlooked in the general debate?

5. What would be desirable effects on the sectorial health level, and on a national level?

\section{References}

1. The International Conference on Primary Health Care. Declaration of Alma-Ata. Available online: https://www.who.int/ publications/almaata_declaration_en.pdf (accessed on 16 January 2021).

2. IAVI. About-IAVI. Available online: https://www.iavi.org/about (accessed on 19 October 2021).

3. Chan, K.M.A.; Boyd, D.R.; Gould, R.K.; Jetzkowitz, J.; Liu, J.; Muraca, B.; Naidoo, R.; Olmsted, P.; Satterfield, T.; Selomane, O.; et al. Levers and leverage points for pathways to sustainability. People Nat. 2020, 2, 693-717. [CrossRef]

4. Abson, D.J.; Fischer, J.; Leventon, J.; Newig, J.; Schomerus, T.; Vilsmaier, U.; von Wehrden, H.; Abernethy, P.; Ives, C.D.; Jager, N.W.; et al. Leverage points for sustainability transformation. Ambio 2017, 46, 30-39. [CrossRef] [PubMed]

5. Bennich, T.; Belyazid, S.; Kopainsky, B.; Diemer, A. Understanding the Transition to a Bio-Based Economy: Exploring Dynamics Linked to the Agricultural Sector in Sweden. Sustainability 2018, 10, 1504. [CrossRef]

6. Meadows, D. Leverage Points: Places to Intervene in a System. Available online: http://www.donellameadows.org/wp-content/ userfiles/Leverage_Points.pdf (accessed on 16 January 2021).

7. The World Bank Group. Kenya Economic Update. Available online: https://openknowledge.worldbank.org/handle/10986/34819 (accessed on 20 October 2021).

8. East African Science and Technology Commission Bioeconomy Strategy for Eastern Africa. Available online: https://easteco.org/ 2019/06/04/bioeconomy-strategy-for-eastern-africa/ (accessed on 19 October 2021).

9. Gatune, J.; Ozor, N.; Oriama, R. The Futures of Bioeconomy in Eastern Africa. J. Futur. Stud. 2021, 25, 1-14. [CrossRef]

10. Jadotte, Y.T.; Leisy, H.B.; Noel, K.; Lane, D.S. The Emerging Identity of the Preventive Medicine Specialty: A Model for the Population Health Transition. Am. J. Prev. Med. 2019, 56, 614-621. [CrossRef]

11. Furnari, S.; Crilly, D.; Misangyi, V.F.; Greckhamer, T.; Aguilera, R.; Fiss, P.C. Capturing causal complexity: A configurational theorizing process. Acad. Manag. Rev. 2020, 46. [CrossRef]

12. Urmetzer, S.; Pyka, A. Understanding Innovation Processes: An Overview of Evolutionary Innovation Models. Available online: https://www.researchgate.net/publication/321747784_Understanding_innovation_processes_An_overview_of_ evolutionary_innovation_models (accessed on 20 September 2020).

13. Nelson, R.R.; Winter, S.G. An Evolutionary Theory of Change; Belknap Press of Harvard University Press: Cambridge, UK, 1982.

14. Klein Woolthuis, R.; Lankhuizen, M.; Gilsing, V. A system failure framework for innovation policy design. Technovation 2005, 25, 609-619. [CrossRef]

15. Casali, E.F. 12 Leverage Points to Bring Change to a Complex System. Available online: https://intenseminimalism.com/2015/1 2-leverage-points-to-bring-change-to-a-complex-system/ (accessed on 30 August 2020).

16. Brief, P. Guidelines for The Appropriate Risk Governance of Synthetic Biology Abbreviations Used in The Text. International Risk Governance Council: Lausanne, Switzerland; ISBN 9782970067269.

17. Marris, C.; Calvert, J. Science and Technology Studies in Policy: The UK Synthetic Biology Roadmap. Sci. Technol. Hum. Values 2020, 45, 34-61. [CrossRef]

18. Breschi, S.; Lissoni, F.; Malerba, F. Knowledge-relatedness in firm technological diversification. Res. Policy 2003, 32, 69-87. [CrossRef]

19. Malerba, F. Sectoral systems of innovation and production. Res. Policy 2002, 31, 247-264. [CrossRef]

20. Dosi, G.; Freeman, C.; Nelson, R.; Silverberg, G.; Soete, L. Review: Technical Change and Economic Theory by Giovanni Dosi, Christopher Freeman, Richard Nelson, Gerald Silverberg, Luc Soete. South. Econ. J. 1990, 55, 1070-1071. [CrossRef]

21. Penrose, E.T. The Theory of the Growth of the Firm; John Wiley \& Sons Inc: New York, NY, USA, $1959 ;$ ISBN 0198289774.

22. Teece, D.J. Towards an economic theory of the multiproduct firm. J. Econ. Behav. Organ. 1982, 3, 39-63. [CrossRef]

23. Juma, C.; Konde, V. The New Bioeconomy-Industrial and Environmental Biotechnology in Developing Countries. Available online: https:// unctad.org/system/files / official-document/poditctedd12.en.pdf (accessed on 20 September 2021).

24. Fuenfschilling, L.; Truffer, B. The structuration of socio-technical regimes-Conceptual foundations from institutional theory. Res. Policy 2014, 43, 772-791. [CrossRef] 
25. Loiseau, E.; Saikku, L.; Antikainen, R.; Droste, N.; Hansjürgens, B.; Pitkänen, K.; Leskinen, P.; Kuikman, P.; Thomsen, M.; Golembiewski, B.; et al. Technology and Institutions in neo-Schumpeterian and Original Institutional Thinking. Res. Policy 2019, $53,1689-1699$

26. North, D.C. An introduction to institutions and institutional change. In Institutions, Institutional Change and Economic Performance; Cambridge University Press: Cambridge, UK, 2012; pp. 3-10.

27. Kogut, B.; Zander, U. Knowledge of the Firm, Combinative Capabilities, and the Replication of Technology. Organ. Sci. 1992, 3, 17-36. [CrossRef]

28. Ivanova, O.; Chatzouz, M. Sectoral Productivity Growth and Innovation Policies. Available online: https://mpra.ub.unimuenchen.de/93488/1/MPRA_paper_93488.pdf (accessed on 20 August 2020).

29. Pyka, A. Informal networking and industrial life cycles. Technovation 2000, 20, 25-35. [CrossRef]

30. Héraud, J.-A.; Kerr, F.; Burger-Helmchen, T. Creative Management of Complex Systems; Wiley-ISTE: London, UK, 2019.

31. Pyka, A.; Mueller, M.; Kudic, M. Regional innovation systems in policy laboratories. J. Open Innov. Technol. Mark. Complex. 2018, 4, 44. [CrossRef]

32. Kim, D.H. Guidelines for Drawing Causal Loop Diagrams. Syst. Think. 1992, 3, 5-6.

33. Bureš, V. A Method for Simplification of Complex Group Causal Loop Diagrams Based on Endogenisation, Encapsulation and Order-Oriented Reduction. Systems. 2017, 5, 46. [CrossRef]

34. Fiss, P.C. Building better causal theories: A fuzzy set approach to typologies in organization research. Acad. Manag. J. 2011, 54, 393-420. [CrossRef]

35. Campagnolo, D.; Cenedese, N. On the applicability of the configurational approach to business model theory with fs/QCA. Acad. Manag. Proc. 2013, 2013, 15366. [CrossRef]

36. Hardy, M.; Bryman, A. Handbook of Data Analysis; SAGE Publications, Ltd: New York, NY, USA, 2012.

37. Institute of Economic Affairs. 8 Facts on the Medical Equipment Leasing Project in Kenya. Available online: https://media. africaportal.org/documents/8_Facts_on_the_Medical_Equipment_leasing_project_i_Kenya.pdf (accessed on 20 August 2020).

38. Ministry of Health-GoK Managed Equipment Service Project on Course. Available online: https://www.health.go.ke/managedequipment-service-project-on-course/ (accessed on 7 March 2021).

39. World Intellectual Property Organization. Budapest Treaty on the International Recognition of the Deposit of Microorganisms for the Purposes of Patent Procedure. Int. Leg. Mater. 1978, 17, 285-311. [CrossRef]

40. Global Bioeconomy Summit Global Bioeconomy Summit Communiqué. Innovation in the Global Bioeconomy for Sustainable and Inclusive Transformation and Wellbeing. 2018. Available online: https://biooekonomierat.de/fileadmin/Publikationen/ empfehlungen/GBS_2018_Communique.pdf (accessed on 20 August 2020).

41. Wield, D.; Hanlin, R.; Mittra, J.; Smith, J. Twenty-first century bioeconomy: Global challenges of biological knowledge for health and agriculture. Sci. Public Policy 2013, 40, 17-24. [CrossRef]

42. Mittra, J. The New Health Bioeconomy RED Policy and Innovation for the Twenty-First Century; Palgrave MacMillan: London, UK, 2015; ISBN 9781137430526.

43. Arora, A.; Belenzon, S.; Patacconi, A. The decline of science in corporate R\&D. Strateg. Manag. J. 2018, 39, 3-32. [CrossRef]

44. Papanastassiou, M.; Pearce, R.; Zanfei, A. Changing perspectives on the internationalization of R\&D and innovation by multinational enterprises: A review of the literature. J. Int. Bus. Stud. 2020, 51, 623-664.

45. Herderschee, J.; Kaiser, K.-A.; Samba, D.M. Resilience of an African Giant: Boosting Growth and Development in the Democratic Republic of Congo; World Bank Publication: Washington, DC, USA, 2011.

46. Yoo, J.; Kim, J. The effects of entrepreneurial orientation and environmental uncertainty on Korean Technology Firms' R\&D investment. J. Open Innov. Technol. Mark. Complex. 2019, 5, 29. [CrossRef]

47. Yun, J.J.; Yang, J.; Park, K. Open Innovation to Business Model: New Perspective to connect between technology and market. Sci. Technol. Soc. 2016, 21, 324-348. [CrossRef] 